INT. J. REMOTE SENSING, 2001, VOL. 22, NO. 15, 2911-2925

\title{
Vegetation mapping of a tropical freshwater swamp in the Northern Territory, Australia: a comparison of aerial photography, Landsat TM and SPOT satellite imagery
}

\author{
K. R. HARVEY* and G. J. E. HILL \\ Faculty of Science, Information Technology and Education and Tropical \\ Savannas CRC, Northern Territory University, Darwin, NT 0909, Australia
}

(Received 26 April 1999; in final form 11 February 2000)

\begin{abstract}
The tropical wetland environments of northern Australia have ecological, social, cultural and economic values. Additionally, these areas are relatively pristine compared to the many other wetland environments in Australia, and around the world, that have been extensively altered by humans. However, as the remote northern coastline of Australia becomes more populated, environmental problems are beginning to emerge that highlight the need to manage the tropical wetland environments. Lack of information is currently considered to be a major factor restricting the effective management of many ecosystems and for the expansive wetlands of the Northern Territory, this is especially the case, as these areas are generally remote and inaccessible. Remote sensing is therefore an attractive technique for obtaining relevant information on variables such as land cover and vegetation status. In the current study, Landsat TM, SPOT (XS and PAN) and large-scale, true-colour aerial photography were evaluated for mapping the vegetation of a tropical freshwater swamp in Australia's Top End. Extensive ground truth data were obtained, using a helicopter survey method. Fourteen cover types were delineated from 1:15000 air photos (enlarged to 1:5000 in an image processing system) using manual interpretation techniques, with $89 \%$ accuracy. This level of detail could not be extracted from any of the satellite image data sets, with only three broad land-cover types identified with accuracy above $80 \%$. The Landsat TM and SPOT XS data provided similar results although superior accuracy was obtained from Landsat, where the additional spectral information appeared to compensate in part for the coarser spatial resolution. Two different classification algorithms produced similar results.
\end{abstract}

\section{Introduction}

The coastal and sub-coastal areas of the Northern Territory contain numerous freshwater wetlands, many of which are listed in the Directory of Important Wetlands in Australia (Jaensch 1993, Whitehead and Chatto 1995). Additionally, 192000 ha of wetlands in the Cobourg Aboriginal Land and Wildlife Sanctuary, and 667000 ha in Kakadu National Park (Stage 1) are listed as Wetlands of International Importance under the Ramsar Agreement. The wetland areas of the Northern Territory provide important habitats for wildlife (e.g. Finlayson et al. 1988, Whitehead

* Now at: EcOz, GPO Box 381, Darwin, NT 0801, Australia; e-mail: kylieharvey@ecoz.cam.au 
et al. 1990) and form a key resource of social, economic and cultural importance to traditional Aboriginal land owners.

A number of threats and management problems can be identified in the Northern Territory's tropical wetland environments. The physical impacts of feral animals (including buffalo, cattle, horses and pigs) are visually evident and have been implicated with other problems such as saltwater intrusion (e.g. Finlayson et al. 1988, Whitehead et al. 1990, Pidsley et al. 1993) and the establishment of noxious weeds (e.g. Finlayson et al. 1988, Whitehead et al. 1990, Storrs and Finlayson 1997). A new threat to the integrity of these wetland ecosystems is the cane toad (Bufo marinus) which will have likely adverse impacts on native fauna as it moves into the higher rainfall areas of the Northern Territory. The potential and actual environmental problems in the tropical wetlands of the Northern Territory highlight the need for restoration and preventative management. Currently such management is hindered by the lack of information available on which to base and justify management interventions.

The paucity of information on wetland areas worldwide can be attributed to the fact that the physical characteristics of wetlands make fieldwork expensive, time consuming and often inexact (Lee and Lunetta 1995). These factors limit fieldwork in wetlands to small areas and restrict the usefulness of the data for extrapolation (Cowardin and Myers 1974, Jensen et al. 1984). Remote sensing, with its utility for surveying large areas in a time and cost effective manner, is a possible solution to difficulties of this type as is illustrated by its successful application to wetland mapping in general (e.g. Cowardin and Myers 1974, Scarpace et al. 1981, Young and Dahl 1994, Lee and Lunetta 1995).

Aerial photography has been a widely used remotely sensed data source for wetland information acquisition both historically and more recently (e.g. Scarpace et al. 1981, Jensen et al. 1984, Hefner and Storrs 1994, Dale et al. 1996, Ozesmi and Mitsch 1997, Mumby et al. 1999). The inherent tradeoff between spectral and spatial resolution in current satellite remote sensing platforms restricts the utility of satellite imagery for mapping wetlands. Wetlands are often spatially characterised by steep ecological gradients with vegetation units narrower than the pixel size of current sensors (e.g. Johnston and Barson 1993, Young and Dahl 1994, Lee and Lunetta $1995)$. Even where the most superior spatial resolution $(10 \mathrm{~m})$ would suffice, the associated inferior spectral resolution may result in the inability to distinguish between different vegetation types, which are often spectrally similar in wetland environments (e.g. Cowardin and Myers 1974, Ernst-Doattavio et al. 1981, Jensen et al. 1984, Catt and Thirarongnarong 1992, Johnston and Barson 1993, Mattheson 1994, Anderson and Perry 1996, Hacck 1996, Phinn and Hill 1998). The textural features and superior spatial resolution of aerial photography make it a very useful data source for detailed wetland mapping, however, this method is not feasible for collecting regional information or information requiring continual validation, because of the cost and logistical difficulties associated with capturing the data (Jennings et al. 1992, Johnston and Barson 1993, Jensen et al. 1993).

Examples of the application of remote sensing (airborne and spaceborne) in tropical wetland environments specifically are limited. Research is required to develop remote sensing methodologies that factor in the extreme environmental conditions experienced in tropical areas. This paper documents a study conducted at Melacca Swamp in the Northern Territory of Australia, a tropical region in which little published work on remote sensing of wetlands is available. The aim of this research was to investigate the utility of remotely sensed data of varying spectral and spatial resolutions for the spectral discrimination of vegetation types within a tropical 
freshwater swamp environment. This was investigated with the ultimate goal of determining which remotely sensed data source is most suited to mapping these environments. Melacca Swamp is a highly heterogeneous, freshwater wetland environment, which provided the opportunity to identify the limits of remote sensing capabilities for monitoring this type of wetland in the region.

\section{The study area}

Melacca Swamp is a permanent freshwater wetland adjacent to the Adelaide River, approximately $50 \mathrm{~km}$ east of Darwin, Northern Territory (figure 1). The swamp drains into Melacca Creek and unlike many of the swamps in the Top End that dry out in the 'dry' season, Melacca Swamp is permanently inundated, with a spring fed creek traversing the southern section (Webb et al. 1983). The area has a high conservation value, as it is one of the most highly utilised nesting habitats of the previously endangered saltwater crocodile (Crocodylus porosus) in the Northern Territory. Melacca Swamp is managed by the Parks and Wildlife Commission of the Northern Territory as a reserve specifically for the conservation of the saltwater crocodile nesting habitat that occurs there (PWCNT 1996).

The Melacca Swamp Conservation Reserve encompasses an area of $23 \mathrm{~km}^{2}$. The southern section of the reserve area was included in this study. The main cover types present are woodlands and open forests of Melaleuca spp. with an understory of Thoracostachyum sumatranum and Phragmites karka sedges. Additionally, some large areas of sedges, namely $T$. sumatranum, $P$. karka and Typha sp., without a canopy of Melaleuca spp. are also present. Open woodland comprising Acacia, Eucalyptus and Melaleuca spp. intermixed with open grassland areas surrounds the swamp, which is bordered by a dense fringe of Melaleuca and monsoon vine-forest species. A large area of floodplain, dominated by numerous grass and sedge species, extends from the eastern extremes of Melacca Swamp to the banks of the Adelaide River. A

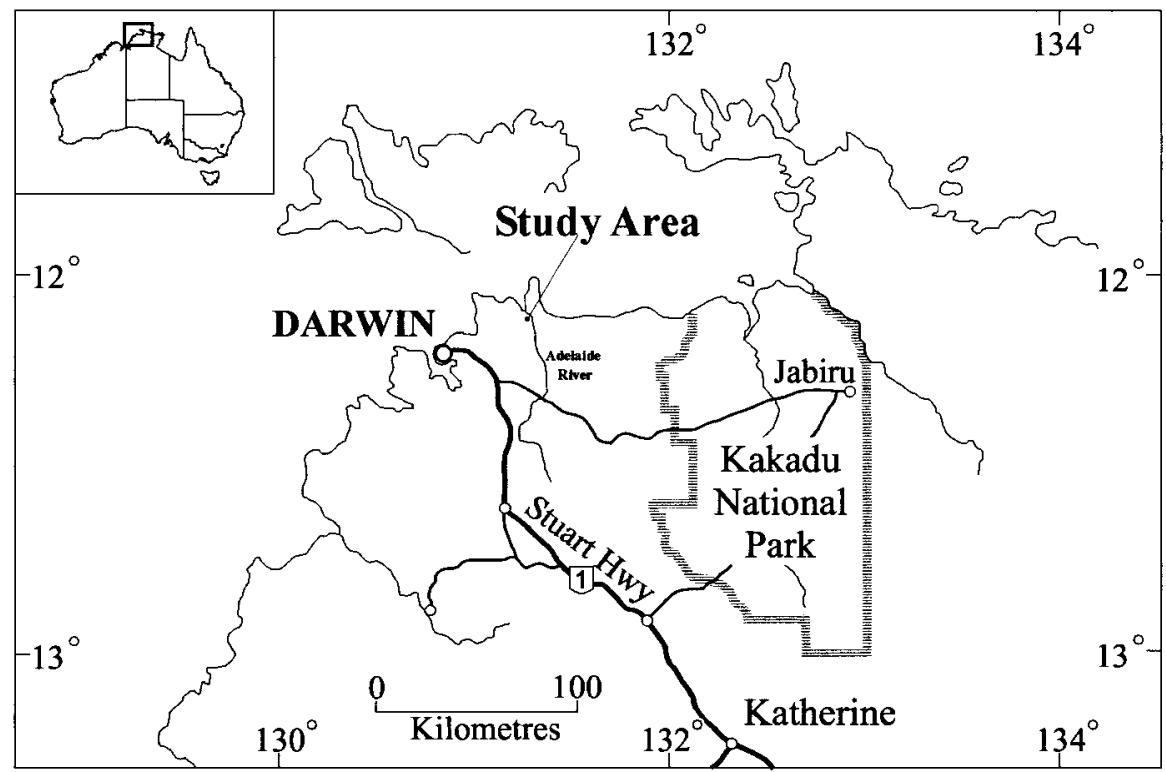

Figure 1. The location of Melacca Swamp in the Northern Territory, Australia. 
band of mangroves follows Melacca Creek from the Adelaide River and at the transition between the saline mangroves and the freshwater swamp vegetation, Typha sp. and Flagellaria indica are dominant (Webb et al. 1983).

The climate of the study area is typical of the monsoonal weather regime that dominates the northern coastal belt of Australia. Two seasons occur, the 'wet' and the 'dry'. These seasons are distinct with large differences in the amount of rainfall and humidity levels. Mean annual rainfall is approximately $1380 \mathrm{~mm}$. Ninety-five per cent of the yearly rainfall occurs during the wet season (November to April) and during these months humidity rises to over $80 \%$ daily. The dry season produces milder weather conditions with a low probability of rainfall and maximum humidity of $67-70 \%$ daily. Temperature does not vary greatly between the seasons with the maximum daily temperatures ranging between $31^{\circ} \mathrm{C}$ (July) and $35^{\circ} \mathrm{C}$ (October).

\section{Methods}

Four remotely sensed data sets of Melacca Swamp were obtained. These were: a Landsat TM image acquired on 20 May 1995; a SPOT XS image acquired on 24 October 1995; a SPOT Panchromatic image acquired on 24 October 1995; and 1: 15000 scale, true colour aerial photography acquired on 4 July 1982. Landsat TM spectral bands two, three, four and five were chosen for this study based on the proven suitability of these bands for wetland studies (e.g. Dottavio and Dottavio 1984, Walsh et al. 1990, Johnson and Barson 1993, Melack et al. 1994). Additionally, bands two, three and four have been identified as useful for determining the presence of a vegetated understory (Congalton et al. 1993), which is characteristic of some cover types in the swamp. All bands of SPOT imagery were purchased.

Processing of satellite imagery and aerial photography was undertaken in the ERDAS Imagine (version 8.3.1) digital image processing system and ArcView GIS (version 3.0). Tools in the microBRIAN digital image processing system were also utilised where the other systems did not provide the functions required.

\subsection{Pre-processing}

Aerial photography was obtained in hardcopy and converted to digital format for computer aided analysis. Each photograph was scanned using a UMAX Mirage D-16L scanner. As increasing the resolution of the scanning procedure did not appreciably improve the visual quality of the scanned photographs, a resolution of 200 dots per inch was used, achieving the desired clarity whilst minimising file storage space.

All data sets were georeferenced to 1:50 000 topographic maps of the study area, which were the largest scale available. Ground control points (GCPs) were selected at locations distinct on both the imagery and topographic maps. Whilst, ideally, GCPs should be as small as a single pixel (Campbell 1996) the nature of the study area, which is mainly comprised of undeveloped open woodland and floodplain areas, made the selection of the appropriate number and distribution of GCPs a challenging task.

A photo basemap was constructed in the form of a continuous mosaic of each individual aerial photo. Each photo was referenced to an arbitrary coordinate system (row/column values). This method was chosen as the area of each photo provided insufficient features for the location of ground control points needed to reference to a standard projection. Once the first photo in each run was referenced to the row/ column coordinate system, each subsequent photo was referenced to the base photo 
through the selection of GCPs in the $60 \%$ area of overlap. Each run was referenced to the adjacent run using the same method, however, the smaller $20 \%$ overlap made the selection of reference points more difficult. Each photo was resampled to the new reference system using the nearest neighbour resampling method.

The referenced photos were mosaiced using the MOSAIC module in Imagine. Afek and Brand (1998) found that the geometric distortions and radiometric differences between adjacent photographs must be corrected to create a seamless mosaic. To achieve this in the aerial photo mosaic of Melacca Swamp, image matching was applied in the overlap area, using a feather function (ERDAS 1997). This matches images by recalculating the pixel values in the overlap area and resulted in a visually smooth transition at the boundaries between each photo and each run in the final image mosaic.

A total of 20 GCPs were established on the Landsat TM image subset and 15 on each of the SPOT scenes. As suggested by Franklin (1993) a first order polynomial equation was adopted to achieve a higher accuracy in the absence of a number of highly accurate GCPs. The RMS error for each of the established GCPs was evaluated and those points with errors representing a ground error of greater than $30 \mathrm{~m}$ were replaced. Resampling was performed using the nearest neighbour algorithm to ensure that the geometric integrity of the data was maintained (Rutchey and Vilcheck 1994, Campbell 1996, ERDAS 1997). Following resampling, examination of the registered imagery sets indicated that registration errors were small, however, the potential for confusion during the fieldwork phase of the project was noted because of the lack of readily identifiable ground points.

Subsets of the Melacca Swamp study area were extracted from each of the registered image data sets. Each subset contained large areas of open woodland and mangrove forest not pertinent to this study and these were masked in an effort to reduce the chances of class confusion in the classification process and to decrease processing time. Various enhancement models were tested on each image to determine the best technique to apply to increase the overall contrast between all cover types. Histogram equalisation provided a suitable method for enhancing Landsat TM and SPOT PAN data, whilst the SPOT XS image was best enhanced using a linear technique.

\subsection{Interpretation of aerial photography}

The referenced mosaic was used as a base map from which cover types present in the swamp were digitised on-screen using the ArcView GIS. A number of display scales were evaluated for the digitising process with a 1:5000 display providing for clearest visual distinction of cover type boundaries. This display scale was maintained for the duration of the digitising process. Vegetation cover types comprising the swamp were manually digitised using tone and texture as the main interpretation cues to define the boundaries between cover types. Each delineated vegetation type was labelled based on the knowledge of an experienced field researcher (B. Ottley). Polygons representing the same vegetation types on the annotated map were merged, having a single entry in the associated attribute table. The resulting coverage was assessed to establish more specific class labels and to identify where misinterpretation of the boundaries may have occurred.

\subsection{Interpretation of satellite imagery}

An unsupervised classification technique was adopted in the analysis of satellite imagery because of the suitability of this approach to areas with complex land cover 
patterns and where fieldwork is difficult (e.g. Stenback and Congalton 1990, Rutchey and Vilcheck 1994, ERDAS 1996, Brady et al. 1997, Menges et al. 1998). In addition to investigating the application of an unsupervised classification technique in a wetland environment, the impact of the algorithm used for the classification was also investigated through the adoption of both minimum distance to mean and isodata classifications.

The minimum distance to mean algorithm assesses the euclidean distance between each pixel value and the means for each class, assigning the pixel to the class from which it has the minimum distance measurement (Harrison and Jupp 1993). A 15\% tolerance level was found to be most suitable for the SPOT XS and Landsat TM imagery, whilst a narrower tolerance of $2 \%$ was required to derive a sufficient number of classes from the SPOT PAN imagery. These tolerance levels were applied to ensure that pixels unrelated to any of the classes in the image remain unclasssified (Harrison and Jupp 1993).

A maximum number of 50 classes was specified for the classification. Following the initial classification the statistics for all classes were viewed. Classes containing only a small number of pixels were deleted, with the criteria for deletion defined by the level of aggregation in the spatial distribution of pixels. The classification was iterated using the new class statistics from the initial classification, minus the small classes. The tolerence level was increased by $1 \%$ in order to ensure that the deleted classes were assigned to their nearest neighbours (Ahmad and Neil 1994).

For the isodata algorithm 50 arbitrary cluster means were initially chosen by default and allowed to shift through an iterative process until a maximum number $(95 \%)$ of unchanged pixels was reached between the final two iterations. The 50 classes produced by the classification represented spectral variation within the imagery but not all classes represented a distinct cover type. Spectrally similar classes exhibiting spatial relationships were merged in an effort to replicate the distribution of cover types at Melacca Swamp. Canonical Variates Analysis (CVA), a separabilty tool provided in the microBRIAN system (CANVAR module), was used to assist in amalgamating classes. The canonical variates transformation matrix calculated during this process was used to create a minimum spanning tree plot which provided a graphical and numerical representation of class separability based on Mahalanobis distance, a measure of euclidean distance between classes, in canonical variate space (Harrison and Jupp 1990, Harrison and Jupp 1993).

Minimum Spanning Trees were prepared for each image classification and used in establishing spectral relationships between classes. This method was chosen as the use of spectral as well as spatial characteristics for class aggregation has been successfully adopted in other studies where classes are spatially contiguous as well as spectrally similar (e.g. Congalton et al. 1993, Ahmad and Hill 1994).

\subsection{Field sampling}

Initial surveys were conducted during the 1997/1998 wet season. Accuracy assessment for the vegetation mapping was completed during the late dry season in August 1998. In this phase of the project, due to the extreme difficulty of moving through the swamp on foot or by boat, and because of the danger posed by crocodiles, a field sampling scheme based on the use of a helicopter was devised. A Kawasaki KH4 model helicopter was used, which dictated that the observers sit on opposite sides, behind the pilot. The use of the helicopter determined the design of the field 
program where locational precision, and sampling efficiency had to be balanced against the cost of relying on this form of reconnaisance.

Four east-west transects were placed $500 \mathrm{~m}$ apart covering the saltwater crocodile nesting area within the swamp. The position of the first transect was determined by the position of the boundary between the swamp and open woodland areas. Five sample points were placed at $1 \mathrm{~km}$ intervals along each transect from the starting position at the boundary between the swamp vegetation and open woodland areas. The east-west extent of the swamp was covered by the sample points.

Each point was labelled and the locational information recorded on data collection sheets for use in the field. In addition, the location of each sample site was recorded in a look-up table, and a point vector file containing each sample site was plotted on the air photo mosaic to aid in the identification of sample sites in the field. This ensured that each site could be found in the event of a GPS malfunction and that disagreements between the programmed GPS reading and the recorded site locations could be easily rectified. At each site, the helicopter was positioned at a height of $20 \mathrm{~m}$ over the sample point (or the nearest identifiable point) and then aligned to record observations to the north, south, east and west. The observers recorded vegetation type at estimated distances of $20 \mathrm{~m}, 50 \mathrm{~m}$ and $100 \mathrm{~m}$ from a line of sight through the helicopter strut. To ensure the correct cover types were recorded, both photographic and written records were collected at each site. This procedure provided 12 observations per sample point and a total sample size of 240 observations for the entire swamp.

\subsection{Accuracy assessment}

Information recorded at each site was incorporated into the field vector file of sampling sites created prior to data collection. The distribution of these ground samples ranged from 25-109 in the generalised cover types derived from satellite data. In the more detailed classes derived from aerial photography the sample sizes ranged from 1-7 for nine of the more restricted cover types and 15-35 for the remaining five classes. The field sample points were overlayed on each of the landcover maps for comparison of classification derived classes and actual ground classes. Points that fell in areas not annotated during the classification process were omitted and points for which the geographic location recorded in the field was dubious were also deleted, resulting in a small variation in sample size in the evaluation of each classification. The correspondance between the classified and ground verified cover types was calculated based on the confusion matrix approach. For the purpose of determining accuracy using this approach, the 240 observations from the multi-stage sampling design were treated as independent observations. Therefore, the confidence intervals derived from this analysis are not absolute.

\section{Results}

Fourteen land cover classes, which adequately described the vegetation types at Melacca Swamp, were derived from interpretation of the aerial photography (figure 2). The overall mapping accuracy, calculated from comparisons between ground truth and mapped data, was $89 \% \pm 5 \%(\mathrm{x} \pm 95 \% \mathrm{CI})$. Individual class accuracies ranged from $82 \%$, for the open sedge class, to $100 \%$ for six of the other classes. Errors of commission and omission were low for virtually all classes. When the classes were aggregated into the three more generic land cover types discernable on the satellite imagery, the overall mapping accuracy increased to $90.6 \% \pm 4 \%$. 

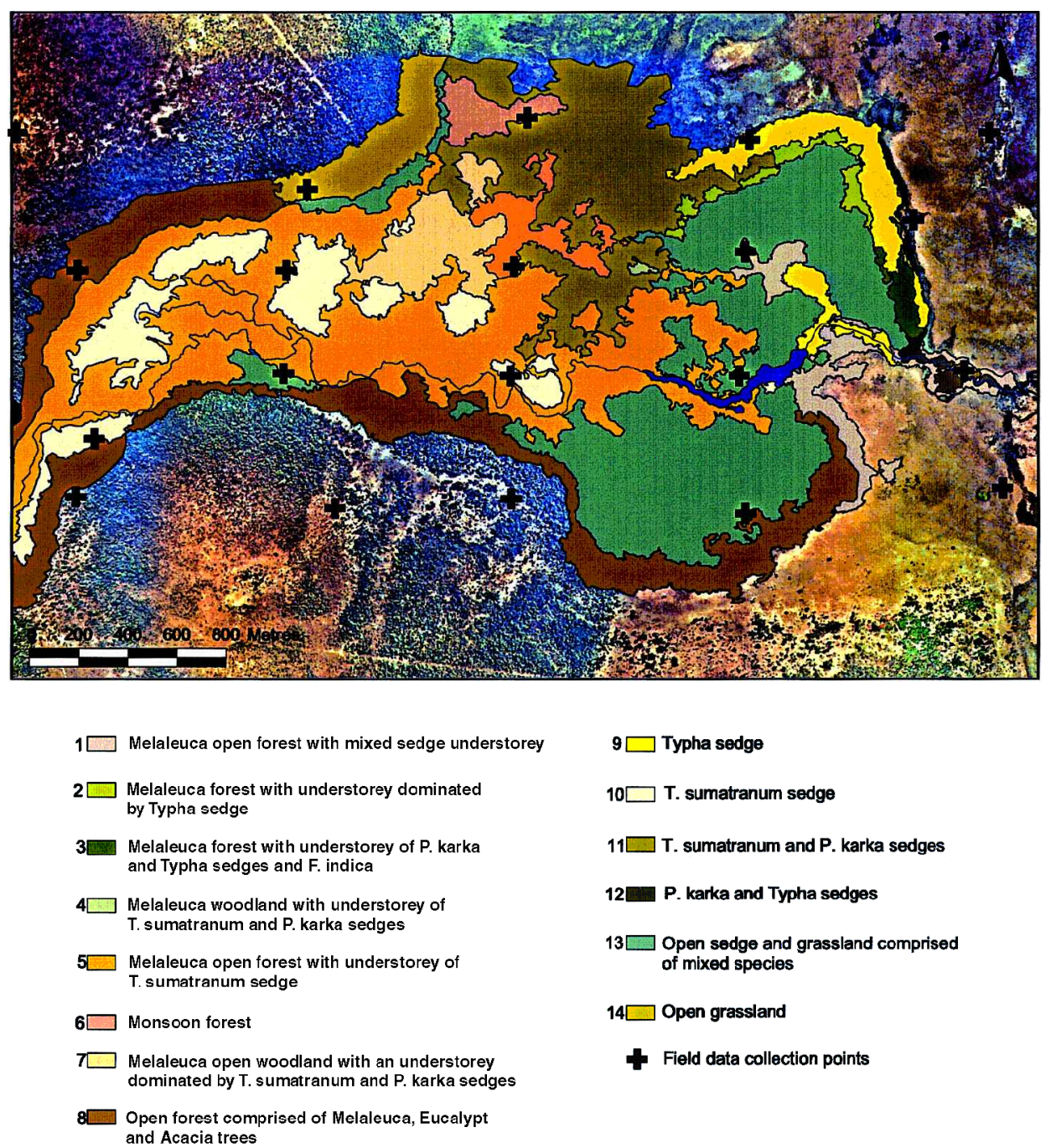

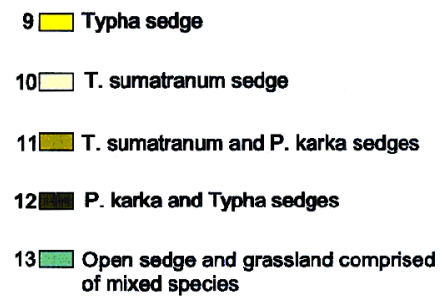

$14 \square$ Open grassland

\section{Field data collection points}

Figure 2. Vegetation map of Melacca Swamp derived from manual interpretation of colour aerial photography.

However, the overall increase in accuracy achieved (5\%), was found to be insignificant $(p \geqslant 0.5)$ when the accuracies of the aerial photo classification both before and after amalgamation were statistically compared.

The detailed information derived from the aerial photography could not be extracted from the Landsat TM, SPOT XS, or SPOT PAN image data analysed. Spectral overlap between quite different vegetation cover types was evident in the classifications derived from the SPOT data but reduced in those derived from the Landsat TM data. An evident restriction on the utility of the Landsat TM satellite imagery for detailed mapping in tropical freshwater wetlands was illustrated by the inability to distinguish between Melaleuca forest with a sedge understory and Melaleuca open woodland with a sedge understory. These vegetation types were successfully delineated on the aerial photography and are a large component of most 
tropical freshwater wetlands in the Northern Territory. To obtain acceptable accuracies $(\geqslant 80 \%)$ from the satellite image data, the vegetation communities had to be reduced to a broader classification consisting of three land-cover classes as illustrated in figure 3 .

The aerial photo classification has a higher level of detail, however, amalgamation of the classes results in a similar classification to that obtained from Landsat TM satellite imagery. Classes 1-8 (figure 2) collectively are similar to the woodland class (class 1) derived from classification of the Landsat TM satellite image. The swamp class dominated by sedges depicted in the Landsat TM classification (class 2) most closely matches the distribution of sedges depicted in the aerial photo classification, however, some misclassifications of sedges and areas comprised of a mixture of grasses and sedges did occur (class 3). The spatial distribution of the areas dominated by grasses and sedges in the Landsat TM and SPOT XS classifications (figure 3) appears to show some correlation with classes 13 and 14 derived from aerial photography (figure 2).

The variation in overall mapping accuracy exhibited by the two different classification algorithms adopted was statistically significant $(p \leqslant 0.05)$. Classification of Landsat TM imagery produced the most accurate result with associated overall

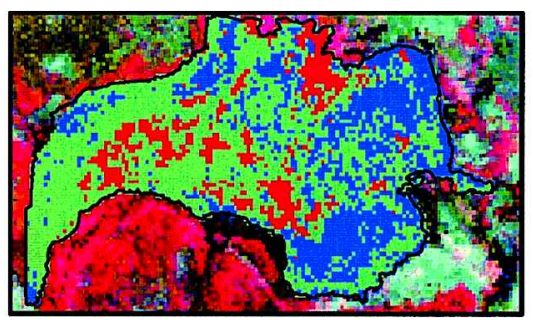

Landsat TM

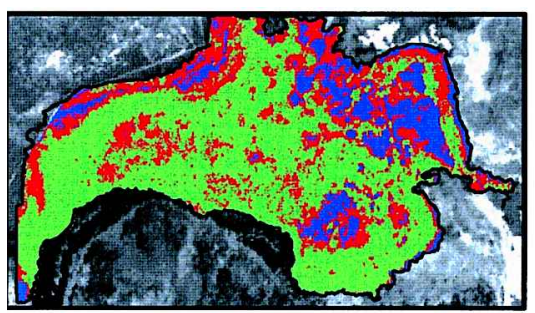

SPOT PAN

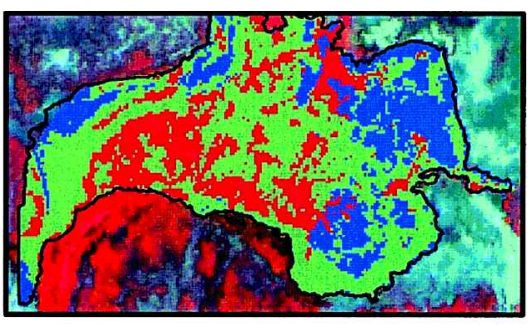

SPOT XS

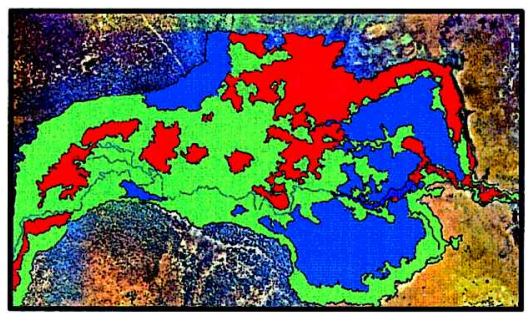

Aerial Photography

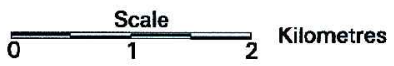

1 Open forest to woodland dominated by Melaleuca trees with an understorey of grasses and sedges

$2 \square$ Dense Thoracostackyum sumatranum and Phragmites karka sedges

$3 \square$ Open sedge and grassland comprising of mixed species

Figure 3. Vegetation associations derived from classification of satellite imagery. 
mapping accuracies of $90 \%$ and $86 \%$ for the minimum distance to mean and isodata algorithms respectively. Classification of the SPOT XS image resulted in a higher mapping accuracy of $85 \%$ using the isodata algorithm and $82 \%$ using the minimum distance to mean algorithm, while analysis of the SPOT PAN image resulted in mapping accuracies of $71 \%$ and $75 \%$ for the minimum distance to mean and isodata algorithms respectively. The results for each image classification are summarised in table 1.

\section{Discussion}

Aerial photography was clearly superior to satellite imagery for detailed mapping of vegetation communities in the tropical wetland environment studied. The superiority of large-scale aerial photography was not an unexpected result and was undoubtedly enhanced through the enlargement of photography $(300 \%)$ within the geographic information system prior to visual interpretation. In addition to the large-scale, it is also noted that the utilisation of interpretation cues, such as context and texture, enhance the class delineation and identification capabilities of aerial photography. These are not extensively utilised in digital image processing (e.g. Ryerson 1989, Franklin 1993, Ahmad and Hill 1994). The use of contextual and textural characteristics to delineate vegetation communities is desirable in wetland environments, especially those with a highly heterogeneous structural composition where similar vegetation communities occur in different densities.

Comparisons of satellite image and aerial photo classifications illustrated that at a structural level (three classes only) aerial photography does not facilitate a significantly higher level of mapping accuracy. Whilst there is no dispute that aerial photography allows for a far more detailed classification, the usefulness of this will depend on the application. When aiming to identify the key structural components of Melacca Swamp, the resolution of the remotely sensed datasets used did not have a large impact on the accuracy of the final classification. The results suggest that either Landsat TM or SPOT XS imagery is adequate for mapping these generalised landcover classes.

With regard to the satellite imagery, the broader spectral range of the Landsat TM data appeared to more than compensate for the superior spatial resolution of the SPOT imagery. Spectral overlap between wetland cover types and wetland and upland cover types is a problem frequently identified in the application of remote sensing techniques to wetland environments (e.g. Johnston and Barson 1993, Sader et al. 1995). Whilst spectral overlap did have an adverse impact on mapping accuracy in this study the impact of this overlap was most significant in the classifications derived from SPOT satellite imagery with inferior spectral resolution. The superior classification accuracies achieved in analysis of Landsat TM imagery data therefore appear to be a function of the data being collected in a wider range of the electromagnetic spectrum, especially in the longer wavelengths which facilitate improved vegetation discrimination (Lee and Lunetta 1994). In particular, the utilization of the middle infrared band $(1.55-1.75 \mathrm{~nm})$, which was not available in the SPOT data, provides improved discrimination of vegetation types, especially in wetland environments (e.g. Cowardin and Myers 1974, Harrison and Jupp 1993, Sader et al. 1995).

An unsupervised classification technique was adopted in this study, as theoretically it was most suited to application in a highly heterogeneous wetland environment. Supervised classification often yields maps with a higher mapping accuracy (e.g. Johnston and Barson 1993, Lyon 1983) however, this technique is not suited to some 


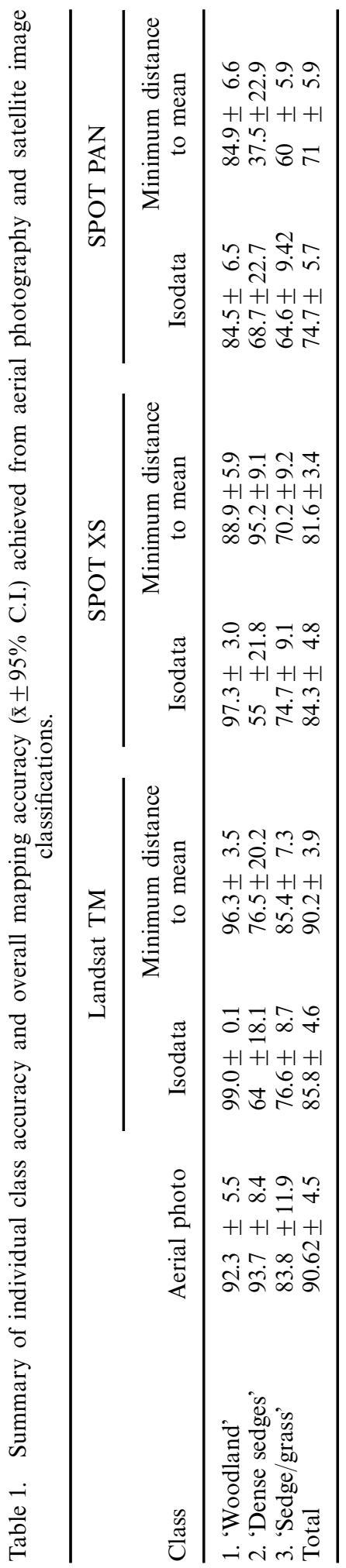


applications. The most useful classification technique will depend on the application and is closely related to the physical characteristics of the features being mapped. Melacca Swamp and most wetland environments in general, consist of a highly heterogeneous arrangement of cover types. This makes supervised classification techniques unsuited to mapping these areas, as statistically homogenous training areas can not be defined. A supervised classification was attempted in this study using aerial photography as a guide for the selection of training areas. However, the technique was abandoned when the training areas selected for each of the cover types showed a significant amount of spectral overlap.

One possible source of error in this study is related to the image acquisition characteristics. A number of remote sensing studies in wetland environments have concluded that spectral overlap may reduce the utility of imagery collected in certain seasons but spectral separability may be improved by optimizing image acquisition (Jensen et al. 1984, Catt and Thirarongnarong 1992, Johnston and Barson 1993). This is especially an issue in tropical wetland environments, which exhibit large annual variation due to the highly seasonal nature of rainfall. These factors may have influenced the accuracy of the vegetation classifications derived in this study. All satellite imagery utilised in this study was acquired in the 'dry' season, which theoretically increases spectral separability due to the reduced influence of water on the spectral response of vegetation cover types. However, the Landsat TM imagery was acquired early in a 'dry' season, which followed an above average wet season rainfall recording for the Top End. In theory this should disadvantage the classification based on the Landsat TM satellite imagery (Harvey et al. 1999), however, superior results were attained over SPOT, which was recorded near the end of the 'dry' season (October). The use of Landsat TM imagery acquired when the landscape is drier may further enhance the utility of these data.

Limitations on data availability are also an issue when mapping remote tropical wetland environments. In this study the aerial photography utilised, despite being the most recent available, was captured 15 years before the field data were gathered. The low frequency of air photo coverage for the region highlights a major problem for mapping and monitoring of tropical wetlands. In the current study the impact was considered to be minimal as the team involved in the annual monitoring of crocodile nesting activity within the swamp report that floristic structure has not altered significantly since the 1980s. The high level of agreement between the map produced from the 1982 photography and the current field data support this observation. However, this is not always the case and often the best available photographic data are panchromatic and at scales of 1:25000 or 1:50000. Very poor discrimination of vegetation communities is available from these data, as is borne out by the results obtained for the SPOT PAN imagery. Given the cost of commissioning and analyzing task-specific air photo coverage of the Top End wetlands, the utility of satellite imagery is therefore a key issue.

The main aim of this research was to determine the utility of remote sensing for mapping vegetation cover types within a tropical freshwater swamp. Aerial photography provided the level of resolution required for a detailed floristic study. This level of detail will be necessary for specific applications, for example, mapping the habitat of waterbirds like the magpie goose (Anseranus semipalmate) which depends on specific vegetation types (grasslands) during the early dry season and different vegetation types (sedgelands) later in the dry season. At a more general level, however, the high levels of accuracy achieved for classification of Landsat TM satellite imagery 
suggest that satellite data provide an adequate description of the major landcover categories characterising this tropical freshwater wetland. The major shortcoming of satellite imagery in this study was its inability to distinguish between different understory types and canopy densities within the wetland environment. This may restrict the usefulness of the satellite data for some applications, for example, delineating hollow trees to provide an assessment of suitability for birds that nest in tree cavities, but not others.

While aerial photography can provide information that cannot be extracted from satellite data, its use is restricted based on the cost of acquiring data over large areas, the time involved in analyzing large datasets and, in many countries, its restricted availability. Therefore, where the required information can be extracted from satellite imagery it appears to be the most feasible technology to adopt. The utility of aerial photography in detailed floristic studies of wetland environments, however, should not be entirely discounted as it remains the most suitable data for small-scale studies and often provides additional information to aid in the analyses of satellite data. As wetland areas come under increasing pressure from human utilization, the ability to map and monitor the status of wetland vegetation communities will be crucial to the conservation of biodiversity. The results of this research, conducted in northern Australia, suggest that remote sensing can aid in management and conservation. Both satellite imagery and aerial photography have a role to play depending on the specific requirements of the research problem. As has been suggested by many previous studies, a multi-level approach where resolution of the imagery is logically linked to the scale of landscape features will provide the most efficient and cost effective methodology.

\section{Acknowledgments}

This research was conducted under sponsorship from the Australian Research Council, Strategic Partnerships with Industry Research and Training scheme. The industry partner, Wildlife Management International Pty Ltd, provided field support and expertise. Brett Ottley, Bryan Baker and Charles Manolis were involved in most facets of the research. Dr Peter Whitehead is thanked for his comments and suggestions on the manuscript. Results will contribute to the program of the Tropical Savannas Cooperative Research Centre and the Northern Territory University, Centre for Tropical Wetlands Management.

\section{References}

Afek, Y., and Brand, A., 1998, Mosaicking of orthorectified aerial images. Photogrammetric Engineering and Remote Sensing, 64, 115-125.

Ahmad, W., and Hill, G. J. E., 1994, A classification strategy for mapping trochus shell habitat in Torres Strait, Australia. Geocarto International, 3, 39-47.

Ahmad, W., and NeIL, D. T., 1994, An evaluation of Landsat Thematic Mapper (TM) digital data for discriminating coral reef zonation: Herron Reef (GBR). International Journal of Remote Sensing, 15, 2583-2597.

Anderson, J. E., and Perry, J. E., 1996, Characterization of wetland plant stress using leaf spectral reflectance: Implications for wetland remote sensing. WETLANDS, 16, 477-487.

Brady, A., Shaikh, M., King, A., and Sharma, P., 1997, Remote sensing and the Great Cumbung Swamp. Wetlands Australia, 7, 6-7.

Campbell, J. B., 1996, Introduction to Remote Sensing, 2nd edn (London: Taylor and Francis Ltd). 
Catt, P., and Thirarongnarong, K., 1992, An evaluation of remote sensing techniques for the detection, mapping, and monitoring of invasive plant species in coastal wetlands: a case study of Para Grass (Brachiaria mutica). Proceedings of the 6th Australasian Remote Sensing Conference, Wellington, New Zealand, 2-6 November 1992 (Committee of the 6th Australasian Remote Sensing Conference Incorporated: Wellington, New Zealand), pp. 200-203.

Congalton, R. G., Stenback, J. M., and Barrett, R. H., 1993, Mapping deer habitat suitability using remote sensing and geographic information systems. Geocarto International, 3, 23-33.

CowArdin, L. M., and Myers, V. I., 1974, Remote sensing for the identification and classification of wetland vegetation. Journal of Wildlife Management, 38, 308-314.

Dale, P. E. R., Chandica, A. L., and Evans, M., 1996, Using image subtraction and classification to evaluate change in sub-tropical intertidal wetlands. International Journal of Remote Sensing, 17, 703-719.

Dottavio, L. C., and Dottavio, D. F., 1984, Potential benefits of new satellite sensors to wetland mapping. Photogrammetric Engineering and Remote Sensing, 50, 599-606.

ERDAS, 1997, ERDAS Field Guide (Atlanta: ERDAS Inc.).

Ernst-Dottavio, C. L., Hoffer, R. M., and Mroczynski, R. P., 1981, Spectral characteristics of wetland habitats. Photogrammetric Engineering and Remote Sensing, 47, 223-227.

Finlayson, C. M., Bailey, B. J., Freeland, W. J., and Fleming, M. R., 1988, In The Conservation of Australian Wetlands, edited by A. McComb and P. Lake (Sydney: Surrey Beatty and Sons), pp. 103-126.

Franklin, J., 1993, Discrimination of tropical vegetation types using SPOT multispectral data. Geocarto International, 2, 57-63.

HAACK, B., 1996, Environmental auditing: monitoring wetland changes with remote sensing: an east African example. Environmental Mangement, 20, 411-419.

HARrison, B. A., and JupP, D. L. B., 1993, MicroBrian Resource Manual (Canberra: CSIRO, Water Resources).

Harrison, B. A., and Jupp, D. L. B., 1990, Introduction to Image Processing-Part Two of the MicroBrian Resource Manual (Canberra: CSIRO Publications).

Harvey, K. R., Duffett, M. L., and Hill, G. J. E., 1999, Identifying and mapping saltwater crocodile (Crocodylus porosus) nesting habitats in the Northern Territory using remote sensing and GIS. Proceedings of the 4th North Australian Remote Sensing and GIS Conference. Darwin, Northern Territory, 28-30 June 1999 (Northern Territory University), Paper \#40 (CD ROM).

Hefner, J. M., and Storrs, C. G., 1994, Classification and inventory of wetlands in the southern Appalachian region. Water, Air and Soil Pollution, 77, 209-216.

JAENSCH, R. P., 1993, Section 5-Northern Territory-Adelaide River floodplain system. In A Directory of Important Wetlands in Australia, 1st edn, edited by S. Ushback and R. James (Canberra: Australian Nature Conservation Agency), pp. 5-8.

Jennnings, C. A., Vohs, P. A., and Dewey, M. R., 1992, Classification of a wetland area along the upper Mississippi River with aerial videography. WETLANDS, 12, 163-170.

Jensen, J. R., Narumalani, S., Weatherbee, O., and Halkard, E. M., 1993, Measurement of seasonal and yearly cattail and waterlily changes using multidate SPOT panchromatic data. Photogrammetric Engineering and Remote Sensing, 59, 519-525.

Jensen, J. R., Christensen, E. J., and Sharitz, R., 1984, Nontidal wetland mapping in South Carolina using airborne multispectral scanner data. Remote Sensing of Environment, 16, $1-12$.

Johnston, R. M., and Barson, M. M., 1993, Remote sensing of Australian wetlands: an evaluation of Landsat TM data for inventory and classification. Australian Journal of Marine and Freshwater Research, 44, 223-232.

LeE, K. H., and Lunetta, R. S., 1995, Wetlands detection methods. In Wetlands and Environmental Applications of GIS, edited by J. G. Lyon and J. McCarthy (USA: CRC Press. Inc), pp. 249-283.

Lyon, J. G., 1983, Landsat derived land-cover classifications for locating potential Kestrel nesting habitat. Photogrammetric Engineering and Remote Sensing, 49, 245-250.

Mattheson, W., 1994, The use of Landsat MSS imagery to determine plant characteristics and community spectral separability from sub-tropical to arid zones in northern Australia. Geocarto International, 2, 5-13. 
Melack, J. M., Hess, L. L., and Sippel, S., 1994, Remote sensing of lakes and floodplains in the Amazon Basin. Remote Sensing Reviews, 10, 127-142.

Menges, C. H., Hill, G. J. E., and Ahmad, W., 1998, Landsat TM data and potential feeding grounds for threatened marine turtle species in northern Australia. Int. J. Remote Sensing, 19, 1207-1221.

Mumby, P. J., Green, E. P., Edwards, A. J., and Clark, C. D., 1999, The cost-effectiveness of remote sensing for tropical coastal resources assessment and management. Journal of Environmental Management, 55, 157-166.

Ozesmi, U., and Mitsch, W. J., 1997, A spatial habitat model for the marsh-breeding Redwinged Blackbird (Agelaius phieniceus) in coastal Lake Erie wetlands. Ecological Modelling, 101, 139-152.

Parks AND Wildlife Commission of the Northern Territory, 1996, A Management Program for Crocodylus porosus and Crocodylus johnstoni-in the Northern Territory of Australia (Darwin: Parks and Wildlife Commission of the Northern Territory).

PhinN, S. R., and Hill, G. J. E., 1998, An integrated multiscale approach for assessing structure and condition of wetland environments in Australia. Proceedings of the $9^{\text {th }}$ Australasian Remote Sensing and Photogrammetry Conference, Sydney, Australia, 20-24 July 1998 (Causal Productions: Sydney), Paper number 40 (CD ROM).

Pidsley, D., Chin, D., and SANDERs, D., 1993, Use of SPOT imagery to map the extent of tidal intrusion into the Mary River floodplain. NARGIS 93-Proceedings of the North Australian Remote Sensing and GIS Forum, Darwin, Australia, 9-11 August 1993 (Canberra: Australian Government Publishing Service), pp. 222-229.

Rutchey, K., and Vilcheck, L., 1994, Development of an Everglades vegetation map using a SPOT image and the Global Positioning System. Photogrammetric Engineering and Remote Sensing, 60, 767-775.

RYERSON, R., 1989, Image interpretation concerns for the 1990s and lessons from the past. Photogrammetric Engineering and Remote Sensing, 55, 1427-1430.

SAder, S. A., Ahl, D., and Wen-Shu, L., 1995, Accuracy of Landsat TM and GIS rule-based methods for forest wetland classification in Maine. Remote Sens. Environ, 53, 133-144.

Scarpace, F. L., Quirk, B. K., Keifer, R. W., and Wynn, S. L., 1981, Wetland mapping from digitized aerial photography. Photogrammetric Engineering and Remote Sensing, 47, 829-838.

Stenback, J. M., and Congalton, R. G., 1990 Using Thematic Mapper imagery to examine forest understory. Photogrammetric Engineering and Remote Sensing, 56, 1285-1290.

Storrs, M. A., and Finlayson, M., 1997, Overview of the conservation status of wetlands of the Northern Territory. Supervising Scientist Report Number 116 (Supervising Scientist: Barton).

Walsh, S. J., CoOper, J. W., Von Essen, I. E., and Gallager, K. R., 1990, Image enhancement of Landsat Thematic Mapper data and GIS data integration for evaluation of resource characteristics. Photogrammetric Engineering and Remote Sensing, 56, 1135-1141.

Webb, G. J. W., Sack, G. C., Buckworth, R., and Manolis, C., 1983, An examination of Crocodylus porosus nests in two northern Australian freshwater swamps, with an analysis of embryo mortality. Australian Wildlife Research, 10, 571-605.

Whitehead P., and Chatto, R., 1995, Northern Territory-Adelaide River floodplain system. In A Directory of important wetlands in Australia-2nd edition, edited by R. Blackley, S. Usback and K. Langford (Canberra: Australian Nature Conservation Agency), pp. $151-154$.

Whitehead P. J., Wilson B. A., and Bowman, D. J. M., 1990, The conservation of coastal wetlands of the Northern Territory of Australia. Biodiversity Conservation, 52, 85-111.

Young, R. D., and DAHL, T. E., 1994, Use of GIS in assessing areas of rapid wetland change. http://wwwsgi.ursus.maine.edu/gisweb/spatdb/gis-lis/gi94105.html 